\title{
CDISC SEND Respiratory Test Name Terminology
}

National Cancer Institute

\section{Source}

National Cancer Institute. CDISC SEND Respiratory Test Name Terminology. NCI

Thesaurus. Code C120535.

Terminology associated with the respiratory test name codelist of the Clinical Data

Interchange Standards Consortium (CDISC) Standard for the Exchange of Non-clinical Data (SEND). 